Electronic Supplementary Information (ESI) for

\title{
Insights into the reactive and deactivation mechanisms of manganese oxides for the ozone elimination: the roles of surface oxygen species
}

Lei Zhang, ${ }^{\mathrm{a}, \mathrm{b}}$ Sheng Wang, ${ }^{*, \mathrm{a}}$ LirongLv, ${ }^{\mathrm{a}, \mathrm{b}}$ Ya Ding, ${ }^{\mathrm{a}, \mathrm{b}}$ Dongxu Tian, ${ }^{\mathrm{c}}$

Shudong Wang a

${ }^{a}$ Dalian National Laboratory for Clean Energy, Dalian Institute of Chemical Physics,

Chinese Academy of Sciences, Dalian, 116023, PR China

${ }^{\mathrm{b}}$ University of Chinese AcademyofSciences, Beijing, 100049, PR China

${ }^{\mathrm{c}}$ School of Chemical Engineering, Dalian University of Technology, Dalian 116024,

China

*Corresponding author: Phone:+86-411-8437-9332,fax: +86-411-8466-2365;

E-mail: wangsheng@dicp.ac.cn

There are 8 pages including 6 figures in the supporting information.

\section{Contents}

1. Details on the catalyst preparation

2. Details on the catalyst characterization 
Figure S1. XRD patterns of the as-prepared $\gamma-\mathrm{MnOOH}$

Figure S2. $\mathrm{N}_{2}$ adsorption and desorption isotherms of the different $\mathrm{MnO}_{\mathrm{x}}$ catalysts $\left(\mathrm{MnO}_{2}-\mathrm{H}-200, \mathrm{MnO}_{2}, \mathrm{Mn}_{2} \mathrm{O}_{3}\right.$ and $\left.\mathrm{Mn}_{3} \mathrm{O}_{4}\right)$

Figure S3. (a) the top plane view of $\beta-\mathrm{MnO}_{2}(110)$, (b) and(c)the sites of oxygen vacancy

Figure S4. (a) the top plane view of $\mathrm{Mn}_{2} \mathrm{O}_{3}$ (211), (b)the sites of oxygen vacancy

Figure S5. (a) the top plane view of $\mathrm{Mn}_{3} \mathrm{O}_{4}$ (200), (b)the sites of oxygen vacancy

Figure S6. FT-IR spectra of $\mathrm{MnO}_{2}-\mathrm{H}-200, \mathrm{MnO}_{2}-\mathrm{H}-200-0.6$ and $\mathrm{MnO}_{2}-\mathrm{H}-200-0.2$.

Figure S7. Ozone conversion over $\mathrm{MnO}_{2}-\mathrm{H}-200$ and the regenerated $\mathrm{MnO}_{2}-\mathrm{H}-200$

Figure S8. The pore size distribution for different $\mathrm{MnO}_{\mathrm{x}}$ catalysts $\left(\mathrm{MnO}_{2}-\mathrm{H}-200, \mathrm{MnO}_{2}\right.$, $\mathrm{Mn}_{2} \mathrm{O}_{3}$ and $\mathrm{Mn}_{3} \mathrm{O}_{4}$ ) calculated by $\mathrm{BJH}$ method

Table S1. Surface Area and pore size distribution of $\mathrm{MnO}_{2}, \mathrm{Mn}_{2} \mathrm{O}_{3}$ and $\mathrm{Mn}_{3} \mathrm{O}_{4}$ 


\section{Details on the catalyst preparation}

Chemicals and reagents: $\mathrm{Mn}\left(\mathrm{CH}_{3} \mathrm{COO}\right)_{2} \cdot 4 \mathrm{H}_{2} \mathrm{O}$ was purchased from Sinopharm Chemical Reagent Co.,Ltd. (Shanghai, China).NaOH, 30\% $\mathrm{H}_{2} \mathrm{O}_{2}$ and absolute ethanol was purchased from Kermel (Tianjin, China). All chemicals were analytical grade and used without further purification.

Preparation of $\gamma-\mathrm{MnOOH}$ : The pristine $\gamma-\mathrm{MnOOH}$ nanorod was synthesized by a redox precipitation process. In a typical synthesis, $6.127 \mathrm{~g} \mathrm{Mn}\left(\mathrm{CH}_{3} \mathrm{COO}\right)_{2} \cdot 4 \mathrm{H}_{2} \mathrm{O}$ was dissolved in deionized water. $20 \mathrm{~mL} 30 \% \mathrm{H}_{2} \mathrm{O}_{2}$ was poured to $50 \mathrm{~mL}$ of $1 \mathrm{M} \mathrm{NaOH}$ aqueous solution, then the $\mathrm{NaOH}-\mathrm{H}_{2} \mathrm{O}_{2}$ solution was slowly added to the above $\mathrm{Mn}\left(\mathrm{CH}_{3} \mathrm{COO}\right)_{2} \cdot 4 \mathrm{H}_{2} \mathrm{O}$ aqueous solution under vigorous stirring. Finally, the asobtained solution was stirred at $60^{\circ} \mathrm{C}$ for 12 h.A brown solid was obtained by hot filtration, which was washed with deionized water and absolute ethanol for several times, finally dried in a vacuum at $60^{\circ} \mathrm{C}$ for $12 \mathrm{~h}$.

Preparation of manganese oxides with different valances: Typically, $\beta-\mathrm{MnO}_{2}$ was prepared by calcining $\gamma-\mathrm{MnOOH}$ precursors at $350^{\circ} \mathrm{C}$ for $4 \mathrm{~h}$ in air. When the temperature reached to $600^{\circ} \mathrm{C}, \alpha-\mathrm{Mn}_{2} \mathrm{O}_{3}$ was obtained. And $\mathrm{Mn}_{3} \mathrm{O}_{4}$ could be prepared via treating $\gamma-\mathrm{MnOOH}$ at $600^{\circ} \mathrm{C}$ for $2 \mathrm{~h}$ in $\mathrm{Ar}$. A certain amount of $\mathrm{MnO}_{2}$ was treated at $200^{\circ} \mathrm{C}$ for $2 \mathrm{~h}$ under a $10 \mathrm{vol} \% \mathrm{H}_{2} / \mathrm{Ar}$ gas flow, which was denoted as $\mathrm{MnO}_{2}-\mathrm{H}-200$.

\section{Details on the catalyst characterization}

The crystalline structure was characterized by X-ray diffraction (PANalytical Empyrean-100, $\mathrm{CuK} \alpha=1.54056 \AA$ ). The morphology of the samples was observed by a JSM-7800F field emission scanning electron microscopy with an accelerating voltage 
of $3 \mathrm{kV}$. And the transmission electron microscopy was done on a JEM-2000. The Raman spectra were recorded on a microscopic confocal Raman spectrometer (Bruker Optics Senterra). X-ray photoelectron spectroscopy was measured in an ESCALAB 250Xi spectrometer and the binding energy was calibrated with the signal for adventitious carbon at $284.6 \mathrm{eV}$. The specific surface areas were determined by $\mathrm{N}_{2}$ adsorption isotherms using a NOVA2200e instrument. All samples were pretreated at $150^{\circ} \mathrm{C}$ for $3 \mathrm{~h}$ under high vacuum. BET specific surface area was calculated by the BET method according to the adsorption branch in the relative pressure range from 0.05 to 0.35 .

Programmed temperature reduction or desorption experiments (TPR or TPD) were carried out using QuantachromeChemiBET 3000 adsorption instrument equipped with a TCD detector. In $\mathrm{H}_{2}$-TPR experiment, $20 \mathrm{mg}$ samples were loaded in a quartz reactor, pretreated at $200^{\circ} \mathrm{C}$ for $2 \mathrm{~h}$ under He gas flow, and cooled to $25^{\circ} \mathrm{C}$, following which the samples were heated to $700^{\circ} \mathrm{C}$ with a $10 \mathrm{vol} \% \mathrm{H}_{2} / \mathrm{Ar}$ gas flow at a heat rate of $10^{\circ} \mathrm{C}$ $\min ^{-1}$. In $\mathrm{O}_{2}$-TPD experiment, $50 \mathrm{mg}$ samples were pretreated at $200^{\circ} \mathrm{C}$ for $2 \mathrm{~h}$ under $\mathrm{He}$ gas flow, and then cooled to $25^{\circ} \mathrm{C}$. Afterwards, the samples were purged with a mixture of $3 \mathrm{vol} \% \mathrm{O}_{2} / \mathrm{He}$ at $25^{\circ} \mathrm{C}$ for $2 \mathrm{~h}$. Desorption of $\mathrm{O}_{2}$ was carried out from $25^{\circ} \mathrm{C}$ to $900^{\circ} \mathrm{C}$ at a heating rate of $5^{\circ} \mathrm{C} \mathrm{min}^{-1}$ purged with $\mathrm{He}$. In $\mathrm{O}_{3}$-TPD experiment after ozone adsorption, 50mg catalysts were pretreated and cooled as described in the above $\mathrm{O}_{2}$ TPD experiment. Then the pretreated and cooled catalysts were kept at $30^{\circ} \mathrm{C}$ for a certain time with 1 vol. $\% \mathrm{O}_{3} / \mathrm{O}_{2}$. Then the resulting samples were further heated to $600^{\circ} \mathrm{C}$ under a $\mathrm{He}$ gas flow at a heating rate of $5^{\circ} \mathrm{C} \mathrm{min}^{-1}$. 
Fouriertransforminfrared spectra (FT-IR) were recorded by Thermal Nicolet 6700 spectroscopy and the scanning range was $650-4000 \mathrm{~cm}^{-1}$.The resolution was of $2 \mathrm{~cm}^{-1} . \mathrm{KBr}$ was added to dilute the sample. 


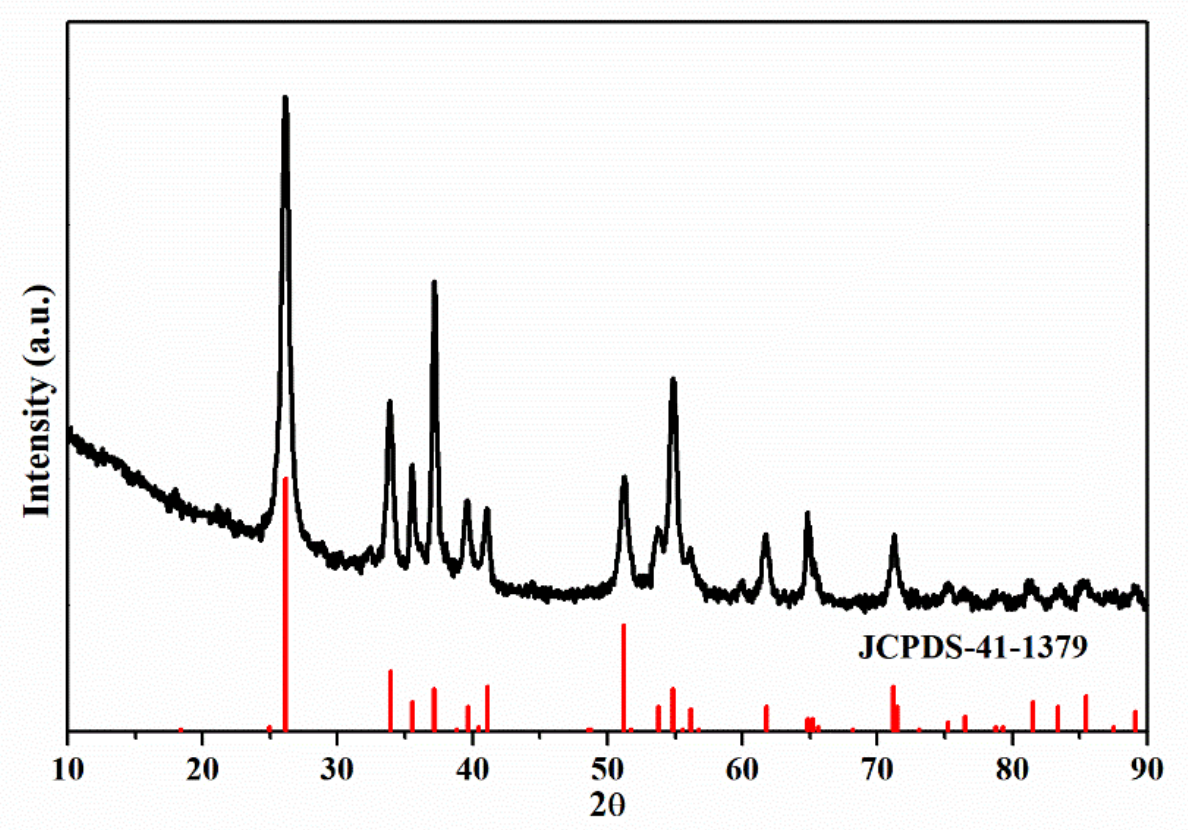

Figure S1. XRD patterns of the as-prepared $\gamma-\mathrm{MnOOH}$

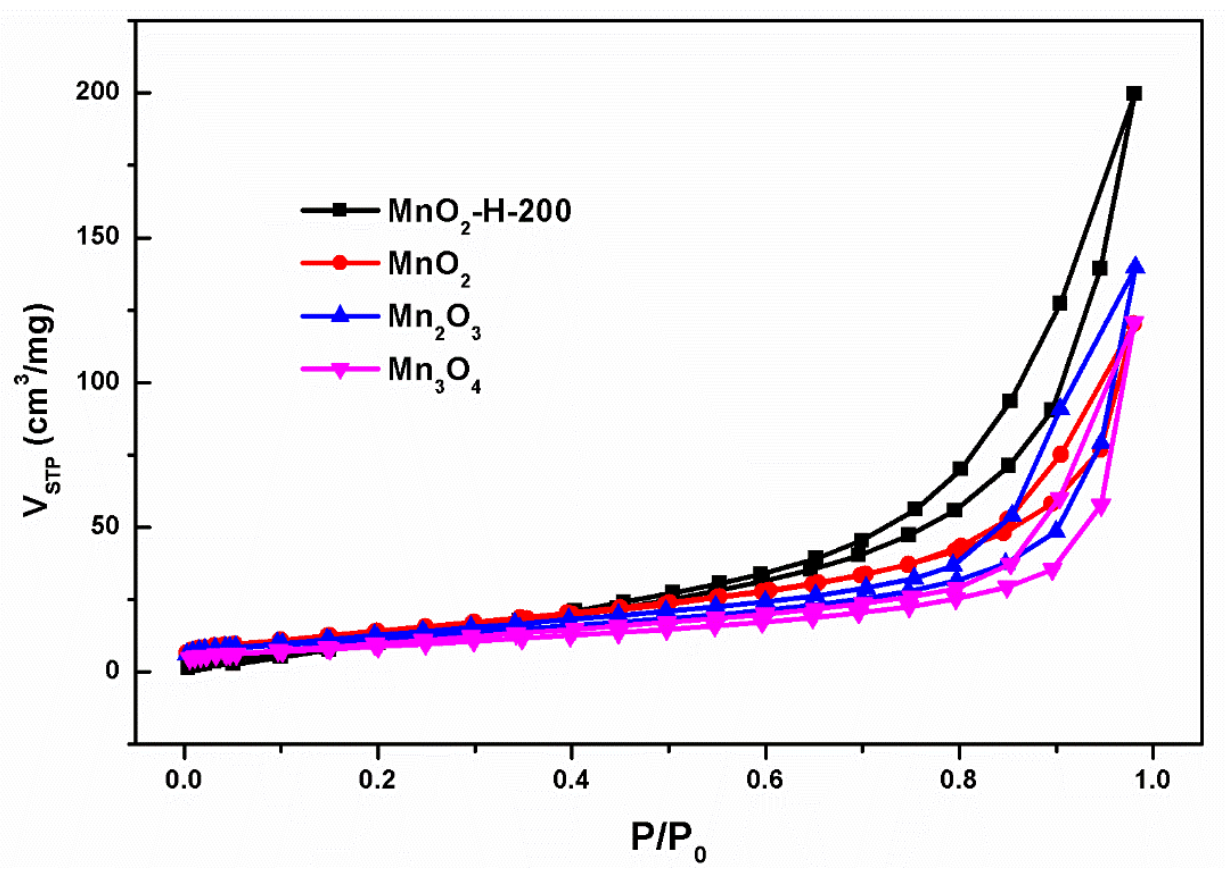

Figure S2. $\mathrm{N}_{2}$ adsorption and desorption isotherms of the different $\mathrm{MnO}_{\mathrm{x}}$ catalysts $\left(\mathrm{MnO}_{2}-\mathrm{H}-200, \mathrm{MnO}_{2}, \mathrm{Mn}_{2} \mathrm{O}_{3}\right.$ and $\left.\mathrm{Mn}_{3} \mathrm{O}_{4}\right)$ 
(a)

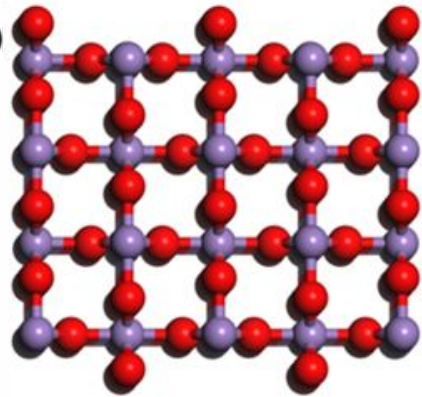

(b)

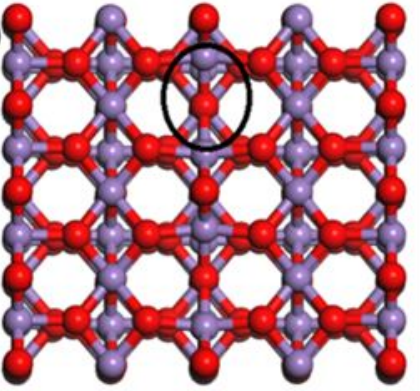

(c)

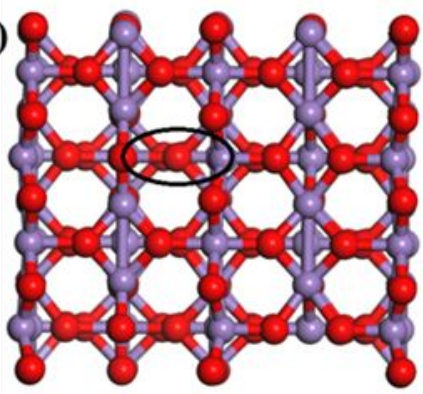

Figure S3. (a) the top plane view of $\beta-\mathrm{MnO}_{2}(110)$, (b) and(c)the sites of oxygen vacancy

(a)

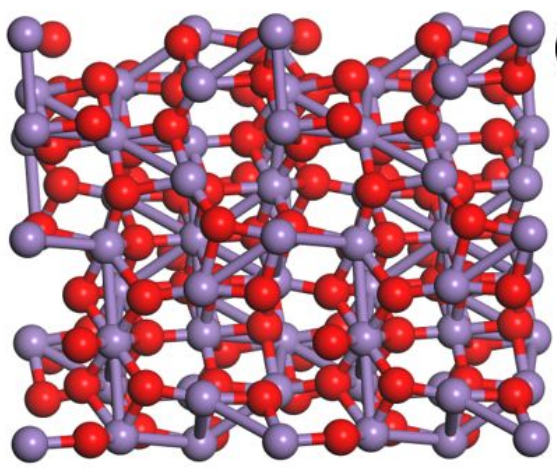

(b)

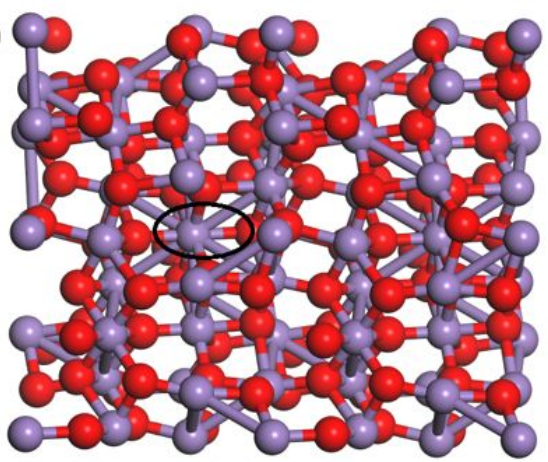

Figure S4. (a) the top plane view of $\mathrm{Mn}_{2} \mathrm{O}_{3}$ (211), (b)the sites of oxygen vacancy

(a)

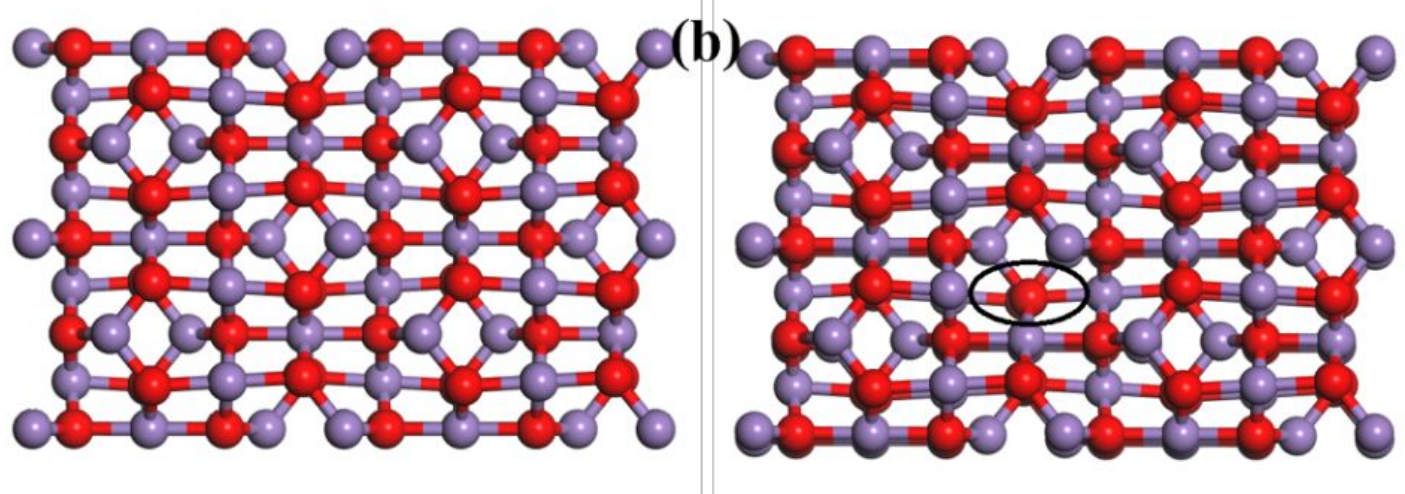

Figure S5. (a) the top plane view of $\mathrm{Mn}_{3} \mathrm{O}_{4}$ (200), (b)the sites of oxygen vacancy 


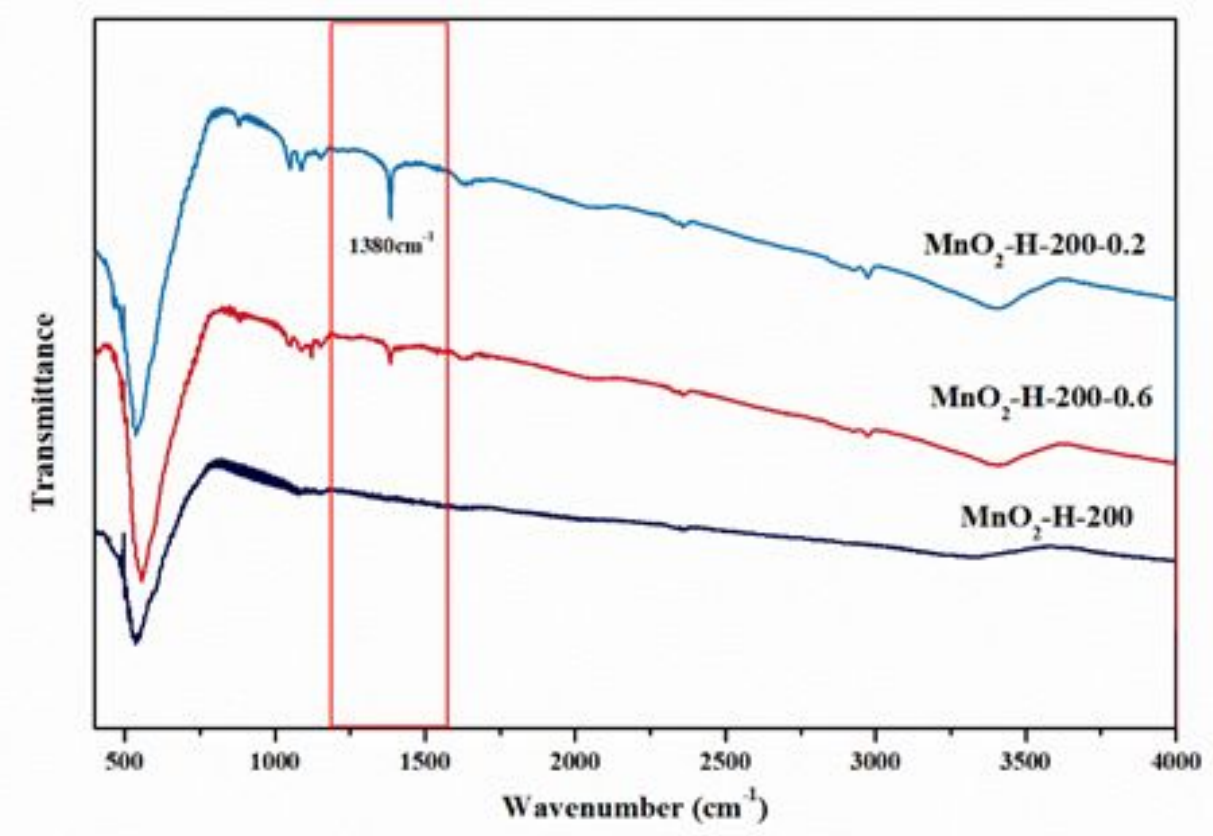

Figure S6. FT-IR spectra of $\mathrm{MnO}_{2}-\mathrm{H}-200, \mathrm{MnO}_{2}-\mathrm{H}-200-0.6$ and $\mathrm{MnO}_{2}-\mathrm{H}-200-0.2$.

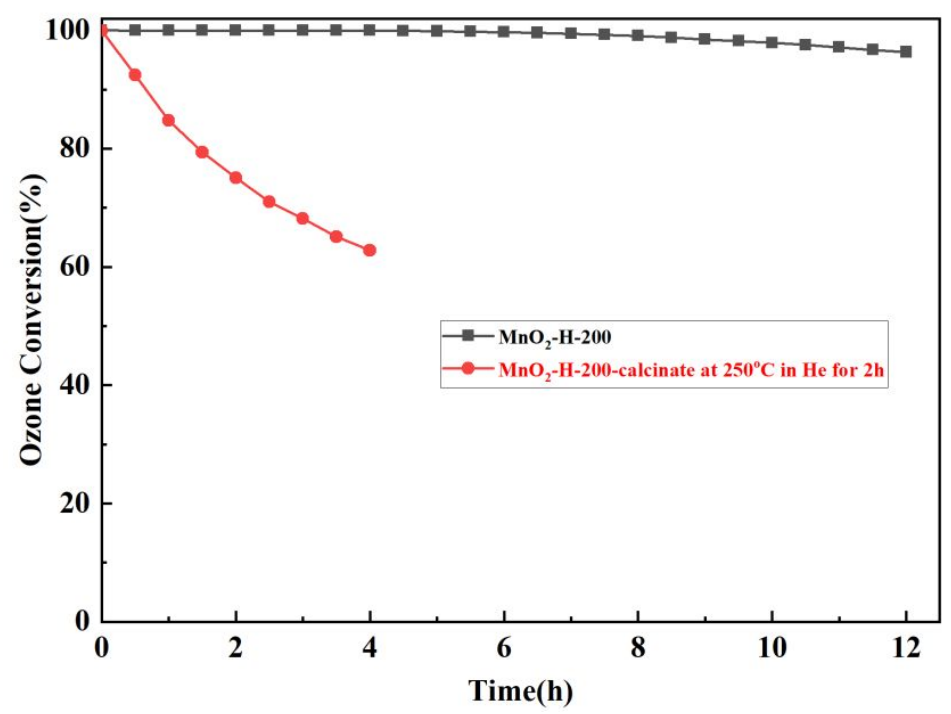

Figure S7. Ozone conversion over $\mathrm{MnO}_{2}-\mathrm{H}-200$ and the regenerated $\mathrm{MnO}_{2}-\mathrm{H}-200$ 


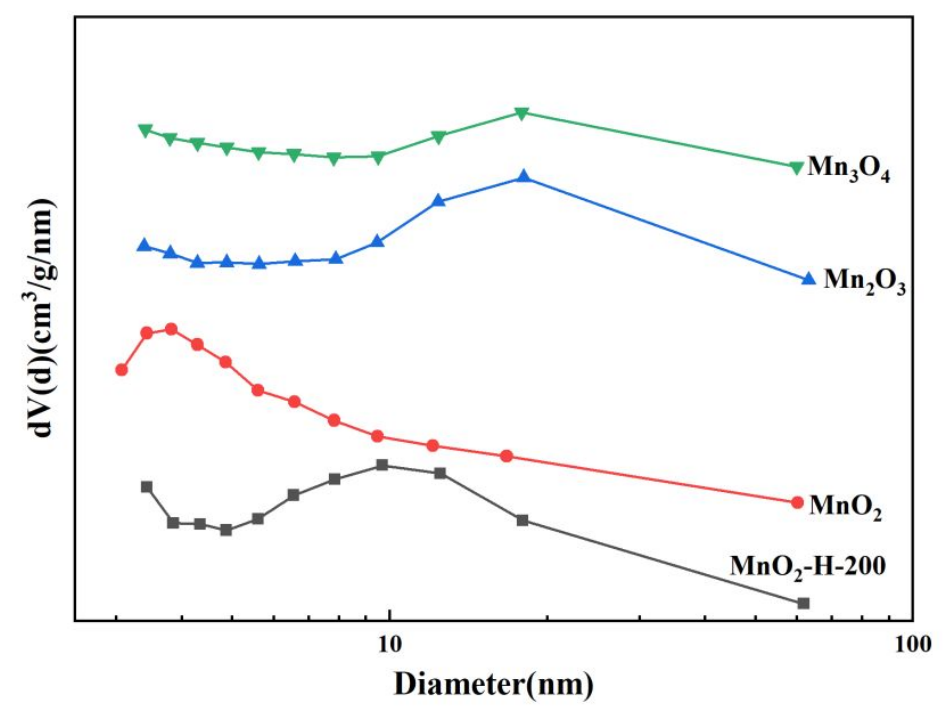

Figure S8. The pore size distribution for different $\mathrm{MnO}_{\mathrm{x}}$ catalysts $\left(\mathrm{MnO}_{2}-\mathrm{H}-200\right.$, $\mathrm{MnO}_{2}, \mathrm{Mn}_{2} \mathrm{O}_{3}$ and $\mathrm{Mn}_{3} \mathrm{O}_{4}$ ) calculated by $\mathrm{BJH}$ method

Table S1 Surface Area and pore size distribution of $\mathrm{MnO}_{2}, \mathrm{Mn}_{2} \mathrm{O}_{3}$ and $\mathrm{Mn}_{3} \mathrm{O}_{4}$

\begin{tabular}{cccc}
\hline & $\begin{array}{c}\text { Surface Area } \\
\left(\mathrm{m}^{2} / \mathrm{g}\right)\end{array}$ & $\begin{array}{c}\text { Pore Volume } \\
\left(\mathrm{cm}^{3} / \mathrm{g}\right)\end{array}$ & $\begin{array}{c}\text { Pore Diameter } \\
(\mathrm{nm})\end{array}$ \\
\hline $\mathrm{MnO}_{2}$ & 54.4 & 0.180 & 3.4 \\
\hline $\mathrm{Mn}_{2} \mathrm{O}_{3}$ & 43.8 & 0.214 & 18.0 \\
\hline $\mathrm{Mn}_{3} \mathrm{O}_{4}$ & 34.8 & 0.183 & 18.9 \\
\hline
\end{tabular}

